\title{
The Trials af a Nature Photographer
}

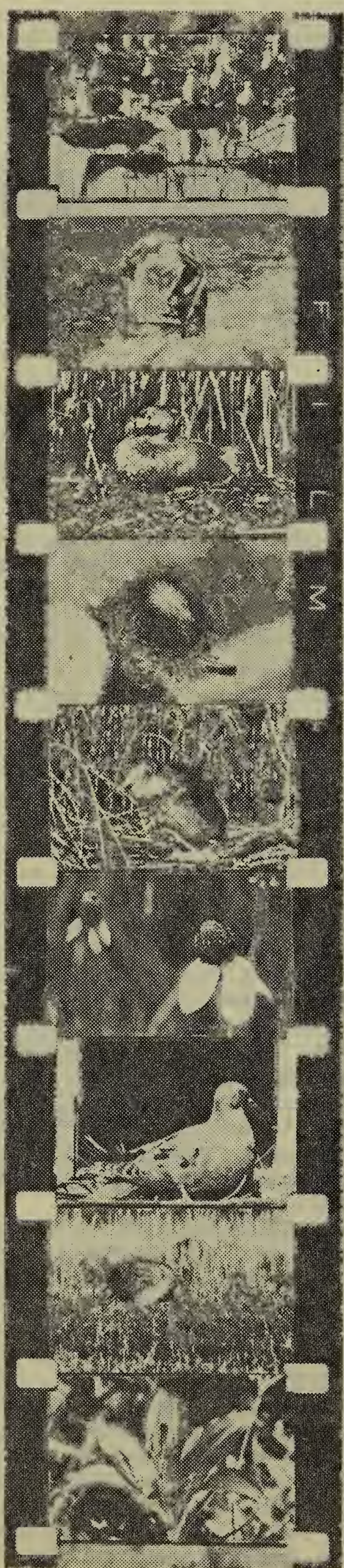

Fred G. Bard

WITH our field activities during the summer.

we are filming Natural History subjects on $16 \mathrm{~mm}$. motion picture at sound speed, and 35 $\mathrm{mm}$. Kodachromes. These we hope will work into extension services to stimulate and assist conservation education in the schools and the public.

When I review some of the events during these picture taking trips, I realize they are of interest to the subscribers in the Blue Jay, and some who are camera enthusiasts. A great deal of enjoyment can be captured by turning back the records of another day as well as contributing to much needed Natural History knowledge. It is our desire through the Blue Jay to encourage these enthusiasts and wherever possible assist them in the problems of picture taking. One of the most interesting pamphlets to read published recently, is a bulletin, "Museum Pictorial" Number one by Alfred Bailey, Director of the Denver Museum of Natural History. This is an accurate interesting approach to the Subject. There is no "hokus pokus," or great secrecy about Nature Photography, all it requires is suitable equipment, and time to allow weather conclitions and behavior of the subject to work cut for the desired results. There are several methods one might use in obtaining Natural History pictures, but there is no question the most suitable is a reflex camera and telephoto lenses. The miniature camera for color or black and white is in a class by itself for still pictures. In addition we are using the motion picture camera for natural history films. We have made a beginning on $35 \mathrm{~mm}$. transparencies by the use of remote controls, but each time it would mean disturbing the subject to wind the film and cock the shutter. Here the owner of telephoto lenses has a distinct advantage. The other accessory that provides us with an opportunity to make the Natural History pictures and observe behaviours, is portable blinds. We have made these from page wire, and by cutting out several of the top strands and doming it over together at the top. This is covered with a cotton covering and painted in camouflage colors. We have on many occasions sat in the blinds and had birds sit on top of the blind, with our ear within an inch or two of the sitting bird. In bird blinds one often has to wait several hours, perhaps the longest this last sunimer, had been six and one half hours at one time. It is disappointing when the birds don't behave the way they should and the weather is anything but ideal, but at the end of each season we find the results sufficiently encouraging to make the entire venture very worthwhile.

This brings to mind a few instances. I will mention these to point out a few of the diffi- 
culties you have to laugh off, then start over again. After having given a show at Yorkton for the Fish and Game league, we travelled back to Ralph Steuck's home at Abernethy to obtain some pictures on the dance of the Shirp-tailed Grouse. We arrived at Ralph's home at one thirty a.m. and hurried off to bed. The alarm rang, and Ralph called me at two thirty, needless to say it was difficult to awaken. Twenty-five minutes from Ralph's home we were well established in the bird blinds and wailed eagerly. Long before dawn, the Sharp-tailed Grouse flew in and by the time daylight was breaking, a total of 60 birds had visited the grounds and were active in dancing. It was still a long wait until sunrise and sufficient light for color photography. I contented myself with the things that were going on arourd me in that quiet spring morning. While it was still dark, I heard a singing Horned Lark high in the sky, and it sang for fully half an hour. Birds sang as they awakened still in the darkness, many night migrants we re identified, passing over. In the stillness of this spring morning, the sun gradually came up amid the chorus of birds, and withe the Sharp-tailed Grouse dancing around me! I recall it as one of the finest spring mornings I can ever remember. There was hardly a breath of air and each sound carried long distances.

As the sun peeped over the horizon, I frequently used the light meter to see how close I was getting to photographic light, by 7 o'clock light was built up to a point where $I$ was able to make the odd shot, perhaps prematurely. By seven thirty the light was now really worthwhile, and I was mentally pushing birds into postition for action shots. Mv attention was then attracted to the tinkling of cowbells, and looking towards the farm nearby, I observed the farmer opening the corral gate, allowing the cattle to go out to pasture. Unhappily the cattle chose to travel through the dancing ground and frightened all the dancing Sharp-tails away. There ended this filming episode.

Another time while on the property of Athol Sweet at Valeport, we had several ideal drumming logs selected for Ruffed Grouse pictures. Blinds had been put up previously and by now we knew the birds were quite at home within the site of the bird blinds. Fred Lahrman, of the Museum, was with me when, after thorough examination, we selected one of the sites where I would stay. The suitable light angle would be in the afternoon, so we contented ourselves, for three hours, filming other subjects, mainly early spring flowers and tree blossoms.

On further examination I had found a site other than the one I had chosen as it seemed to be more suitable. The grouse were drumming steadily and the situation looked ideal. Fred had not returned when I chose to enter the blind, so I left a note for him at the steering wheel. telling him where I would be.

After waiting for about two hours I noticed the bird walking along the woodland floor to its drumming log. When within a foot or two of the drumming log, my companion, intent on nature subjects, walked through the woods close enough to the blind to frighten the grouse away. So ended my first attempt. We agreed that there was still time to obtain pictures so I again entered the blind. Within an hour and a half after entering, the birds returned to drum on the log. Its performance was beautiful, and I was quite happy with the results. But alas! on changing the film I found that the sprocket had torn the film and I hadn't exposed a foot. There ended attempt number two.

Not the least bit discouraged we decided to return another day. On our arrival at the abandoned farm buildings, we obtained a few flower pictures and waited for the angle of the sur to be about right before entering the blinds. About the time the light was right a farm truck drove into the yard. These were salvage people who had purchased a stationary engine and chose to break it up with sledge hammers in order to load it into the truck. Needless to say, with all that noise around, the birds simply didn't show up that afternoon. In the season of 1952 we will return and I hope will be successful in obtaining the pictures of the Ruffed Grouse.

Mr. Lahrman was established at M a d ge L ake to collect faunal material for the Museum and had located several ideal nesting sites for pictures. The first we chose to photo- 
graph was that of the Loon. Sitting on an orange packing box, in hip waders, I waited inside the blind for the birds to return. However, after spending two hours in the blind, something happened to the packing box. I noticed the angle of vision seemed to be getting lower all the time. Then I became aware that I was sitting within one half inch of the surface of the water - the packing case had simply collapsed. Well, the Loons had to be abandoned for the time being. On another occasion at another Loon nesting site, the adult birds were working close to the nest and I was quite sure of obtaining pictures with in a few minutes, when a Bittern walked in and stood near the nest. The Loons made several lunges to drive the birds away but were not successful. After waiting five and a half hours, I was not able to take any pictures of Loons on their nests.

On e afternoon while obtaining footage of young Red-winged Blackbirds being fed by their parents, my best sequence shot ended with the female swallowing the excreta of the young. I was hoping that she would carry them away as she usually does.

One dull rainy afternoon we found three young Bitterns in a nest. Two backed away with a hissing noise, intended to frighten. The third gave the samc hissing noise but through the opened mouth we noticed a skin covering, like a fish bladder. It appeared bluish grey and filled the throat cavity. The neck was distended and stiff to the touch. We had seell nothing like this before. Unfortunately the rain prevented our taking pictures.

On Wascana Lake, one day this fall, I saw a spider resting on the water surface. It was large and appeared to measure one and threequarters inches across. The camera was set up on the tripod for two hours waiting for the sky to brighten. As time passed it grew darker so I packed the camera. All this time the spider remained motionless. Taling one of the marsh grasses I touched the spider, thinking it would scurry for cover. Instead it drew in its legs and disappeared beneath the surface of the water. Some day I hope to find out more about this spider.

Hunting and Fishing is sport, but it never compares with the satis- faction of obtaining good Natural History pictures. There is the satisfaction of achievement and the joy of seeing your subject free to continue its interesting life.

In bringing you a $f$ e $w$ of our treasures I would like to emphasize that "there is no magic about obtaining these Natural History pictures -- it o n l y requires the equipment and the patience to wait." Speaking from a Museum point of view, I am willing to assist anyone interested in beginning this type of activity. The results will reward you for your interest.

In this respect I would like to add my sincere thanks to our editor, Mr. Lloyd Carmichael, for the excellent progress he is making in photographing our wild flowers; also to Mr. Fred Lahrman, of the Museum, who is doing similar work. These fine Kodachrome stills are being added to our library. When ready for distribution to the schools they will be appreciated by many.

\section{The Wonderful Ways of Nature}

E. T. Scott, Regina

MY sister, who lives in Sarnia, was telling me of a Robin that had her nest in one of the nearby trees, on their property.

On this particular day the Robin was frantically flying around my sister, cbviously trying to attract her attention.

The conduct of the bird being similar to that of a distraught mother when her child was in danger, caused my sister to make an immediate investigation in an effort to determine the cause of this unusual conduct. The nest was not too high for inspection.

My sister got to the nest and found that one of the younsters had attempted to swallow a worm that was far too large for its throat. The Mother Bird could not remove the worm without aid, so she hurriedly sought it forthwith, and the first person that she saw happened to be my sister, who was able to remove the obstruction from the choking child.

The Mother bird was placated, the wee one was saved from choking to death, and sister went on her way, more amazed then ever at the wonderful ways of Nature! 